\title{
SYNTHESIS AND CRYSTAL STRUCTURE ANALYSIS OF 4-(2- (4-CHLORO-PHENYL)-4,5-DIPHENYL-1H-IMIDAZOLE-1-YL)- 2,3-DIMETHYL-1-PHENYL-1,2-DIHYDROPYRZOL-5-ONE
}

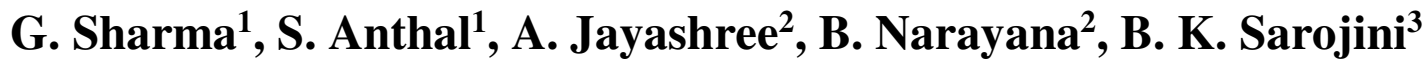 \\ and R. Kant ${ }^{1} *$ \\ ${ }^{1} \mathrm{X}$-Ray Crystallography Laboratory, Department of Physics, University of Jammu, \\ Jammu Tawi-180006, India. \\ ${ }^{2}$ Department of Studies in Chemistry, Mangalore University, Mangalagangotri-574 199, India. \\ ${ }^{3}$ Department of Industrial Chemistry, Mangalore University, Mangalagangotri-574 199, India. \\ *E-mail: rkant.ju@gmail.com
}

\begin{abstract}
The title compound, 4-(2-(4-Chlorophenyl)-4,5-diphenyl-1H-imidazole-1-yl)-2,3-dimethyl-1-phenyl-1,2dihydropyrzol-5-one $\left(\mathrm{C}_{32} \mathrm{H}_{25} \mathrm{ClN} \mathrm{N}_{4} \mathrm{O}\right)$, crystallizes in the monoclinic crystal system with space group $\mathrm{P} 2_{1} / \mathrm{c}$ with unit cell parameters: $a=7.7847(7) \AA, b=17.5077(14) \AA, c=19.8332(19) \AA, \beta=92.783(8)^{\circ}$ and $Z=4$. The crystal structure has been solved by using direct methods and refined by full matrix least-squares procédures to a final Rfactor of 0.085 for 1944 observed reflections. In the crystal structure, molecules are linked by $\mathrm{C}-\mathrm{H} \cdots \mathrm{O}$ intermolecular hydrogen bonds, forming chains along b-axis. The structure also exhibits $\mathrm{C}-\mathrm{H} \cdots \pi$ interaction and intramolecular $\mathrm{H}$-bonds of the type $\mathrm{C}-\mathrm{H} \cdots \mathrm{N}$.
\end{abstract}

Keywords: Crystal Structure, Imidazole, Pyrazole, Direct Methods, Intermolecular interaction.

(c) RASĀYAN. All rights reserved

\section{INTRODUCTION}

Imidazole and pyrazole scaffolds display improved efficacy and show potential antibacterial and antifungal activities ${ }^{1}$. Imidazole and its derivatives have a long history of applications in the agrochemical and pharmaceutical industry. These systems possess a wide spectrum of pharmacological activities such as anti-convulsant ${ }^{2}$, antitubercular ${ }^{3}$, anti-inflammatory ${ }^{4}$, antimicrobial ${ }^{5}$, anticancer and anti-Parkinson ${ }^{6}$. Pyrazole is well established in the literature as important biologically active heterocyclic compounds due to their widespread potential biological and pharmacological activities ${ }^{7}$. They have shown significant biological activities, such as anti-microbial ${ }^{8}$, analgesic ${ }^{9}$, anti-inflammatory ${ }^{10}$ and anticancer $^{11}$ activities $^{-}$ and in view of these pertinent features that we got interested in the synthesis and structure analysis of 4-(2-(4-Chlorophenyl)-4,5-diphenyl-1H-imidazole-1-yl)-2,3-dimethyl-1-phenyl-1,2-dihydropyrzol-5-one.

\section{Synthesis}

\section{EXPERIMENTAL}

A mixture of benzil $(0.210 \mathrm{~g}, 1.0 \mathrm{mmol}), 4-$ Aminoantipyrine $(0.203 \mathrm{~g}, 1.0 \mathrm{mmol})$, 4-Chlorobenzaldehyde $(0.140 \mathrm{~g}, 1.0 \mathrm{mmol})$, ammonium acetate $(0.077 \mathrm{~g}, 1.0 \mathrm{mmol})$ and $\mathrm{ZnO}$ nanoparticles $(0.008 \mathrm{~g}, 0.1 \mathrm{mmol})$ in glacial acetic acid $(15 \mathrm{~mL})$ was stirred for 3 hours. The progress of the reaction was monitored by TLC. After completion of the reaction, the mixture was cooled to room temperature. The reaction mixture was then poured into cold water. The solid separated was filtered by suction to afford crude product. The pure product was obtained by further recrystallization from ethanol. Single crystal of the purified product was developed from acetone by a slow evaporation method (M.P.: 483-485K). The reaction scheme of the compound is given in Fig.-1.

Rasayan J. Chem., 12(2), 773-779(2019)

http://dx.doi.org/10.31788/RJC.2019.1225157

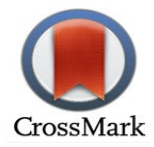


RASĀYAN J. Chem.

Vol. 12 | No. 2 |773 - 779| April - June | 2019
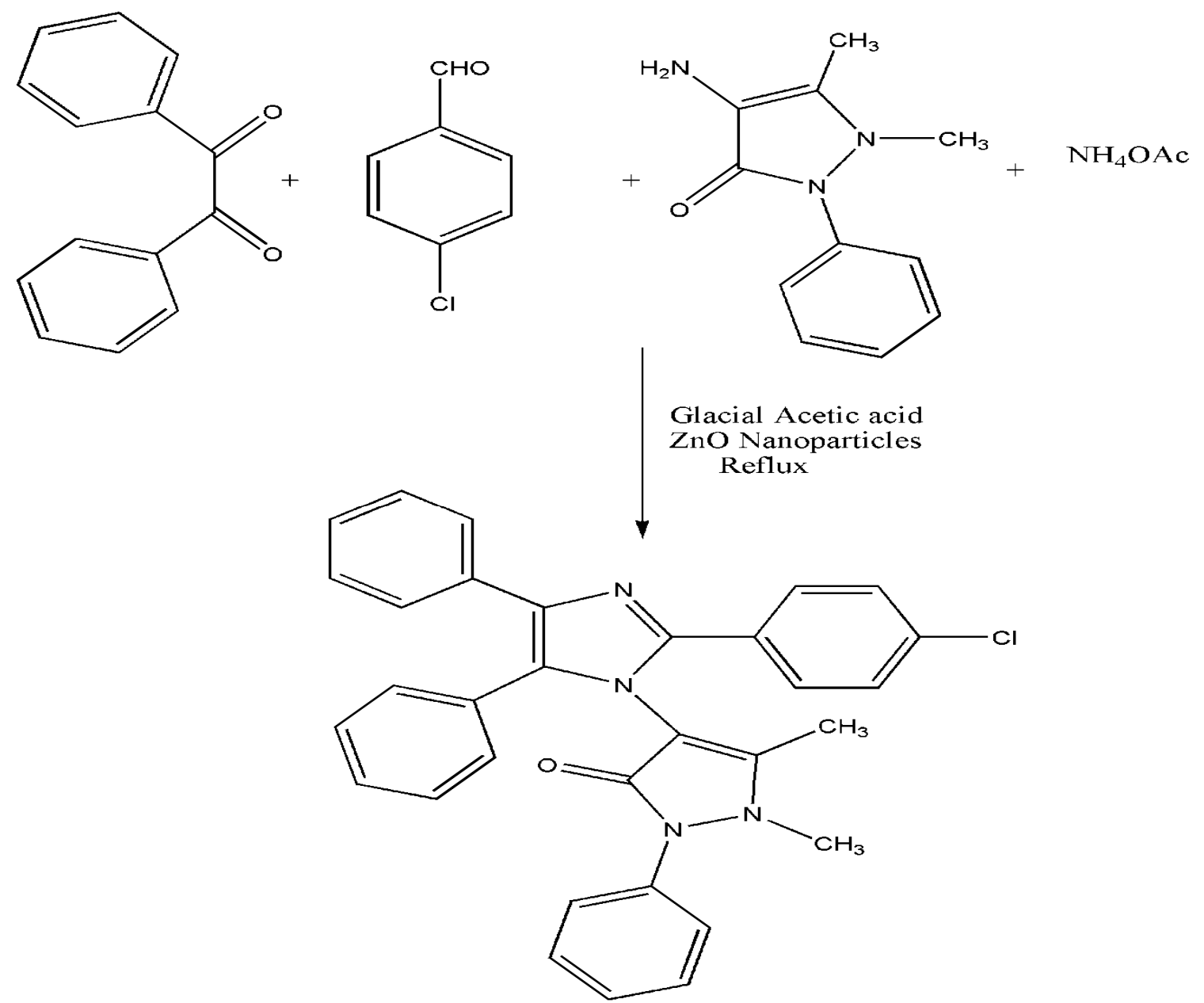

Fig.-1: Reaction Scheme for the Preparation of 4-(2-(4-Chlorophenyl)-4,5-Diphenyl-1H-imidazol-1-yl)-2,3dimethyl-1-phenyl-1,2-dihydropyrzol-5-one.

\section{Crystal Structure Determination}

$\mathrm{X}$-ray intensity data of the crystal of dimensions $0.30 \mathrm{X} 0.20 \mathrm{X} 0.20 \mathrm{~mm}^{3}$ was collected on $X^{\prime}$ calibur CCD area-detector diffractometer equipped with graphite monochromated $\operatorname{MoK} \alpha$ radiation $(\lambda=0.710 \AA)$. X-ray intensity data of 9883 reflections were collected at 293(2) K and out of these reflections 4705 were found unique. The intensities were measured by $\omega$ scan mode for $\theta$ ranges $3.5^{\circ}$ to $25^{\circ}$. 1944 reflections with $\mathrm{I}>2 \sigma$ (I) were treated as observed. Data were corrected for Lorentz-polarization and absorption factors. The structure was solved by direct methods using SHELXS97 ${ }^{12}$ and was refined using SHELXL97 ${ }^{12}$. All non-hydrogen atoms of the molecule were located from the best E-map. All the hydrogen atoms were geometrically fixed and allowed to ride on the corresponding carbon with $\mathrm{C}-\mathrm{H}=$ $0.93-0.97 \AA$. The final refinement cycles converged to an $\mathrm{R}$-factor of 0.085 and $w \mathrm{R}\left(\mathrm{F}^{2}\right)=0.1863$ for 1944 observed reflections. Residual electron densities range from -0.28 to $0.27 \mathrm{e}^{-3}$. Atomic scattering factors were taken from International Tables for X-ray Crystallography (1992, Vol. C, Tables- 4.2.6.8 and 6.1.1.4). The Geometry of the molecule was calculated using the WinGX ${ }^{13}$, PARST $^{14}$ and PLATON ${ }^{15}$ software.

Crystallographic information has been deposited at the Cambridge Crystallographic Data Centre with CCDC number 1507484. The crystallographic and refinement data of the crystal is given in Table-1.

\section{RESULTS AND DISCUSSION}

The molecular structure containing atomic labeling is shown in Fig.-2 (ORTEP) ${ }^{16}$. The molecular structure consists of three phenyls, one chlorophenyl, one imidazole and one pyrazole rings. All the rings, as such, are planar. Bond distances, bond angles and torsion angles which play an important role in 
collating the structural properties of this molecule are presented in Table-2. The bond distances and bond angles of all the four six-membered rings show a normal geometry ${ }^{17}$. The $\mathrm{C}-\mathrm{N}$ bond distances are comparable with the values observed for some analogous structures ${ }^{18,19}$. The N3-N4 distance of $1.385(5) \AA$ is significantly larger than the standard value of $1.350 \AA$. The deviation in the values of bond angles C25-C24-N4 $\left[122.4(4)^{\circ}\right]$ and $\mathrm{C} 24-\mathrm{N} 4-\mathrm{C} 32\left[125.9(4)^{\circ}\right]$ is partially due to the torsion present along with the $\mathrm{C} 24-\mathrm{N} 4$ bond (torsion angle $\mathrm{C} 25-\mathrm{C} 24-\mathrm{N} 4-\mathrm{C} 32=14.4^{\circ}$ ). The chlorophenyl ring makes a dihedral angle of $40.65^{\circ}$ and $84.03^{\circ}$ with the imidazole and pyrazole rings, respectively. The phenyl rings (A \& B) are twisted by $72.36^{\circ}$ and $11.26^{\circ}$, respectively, with respect to the imidazole ring. The pyrazole ring is held almost right angle to the imidazole ring as indicated by the dihedral angle being $89.46^{\circ}$.

In the crystal structure, there exists one intramolecular interaction [C13-H13...N1] and an intermolecular hydrogen bond [C16-H16...O1] that links the molecules into chains along b-axis [Fig.-3 (Mercury) $]^{20}$. The details of intra/inter-molecular hydrogen bonds are given in Table-3. The C-H... $\pi$ contacts as observed in the molecular packing are given in Table-4.

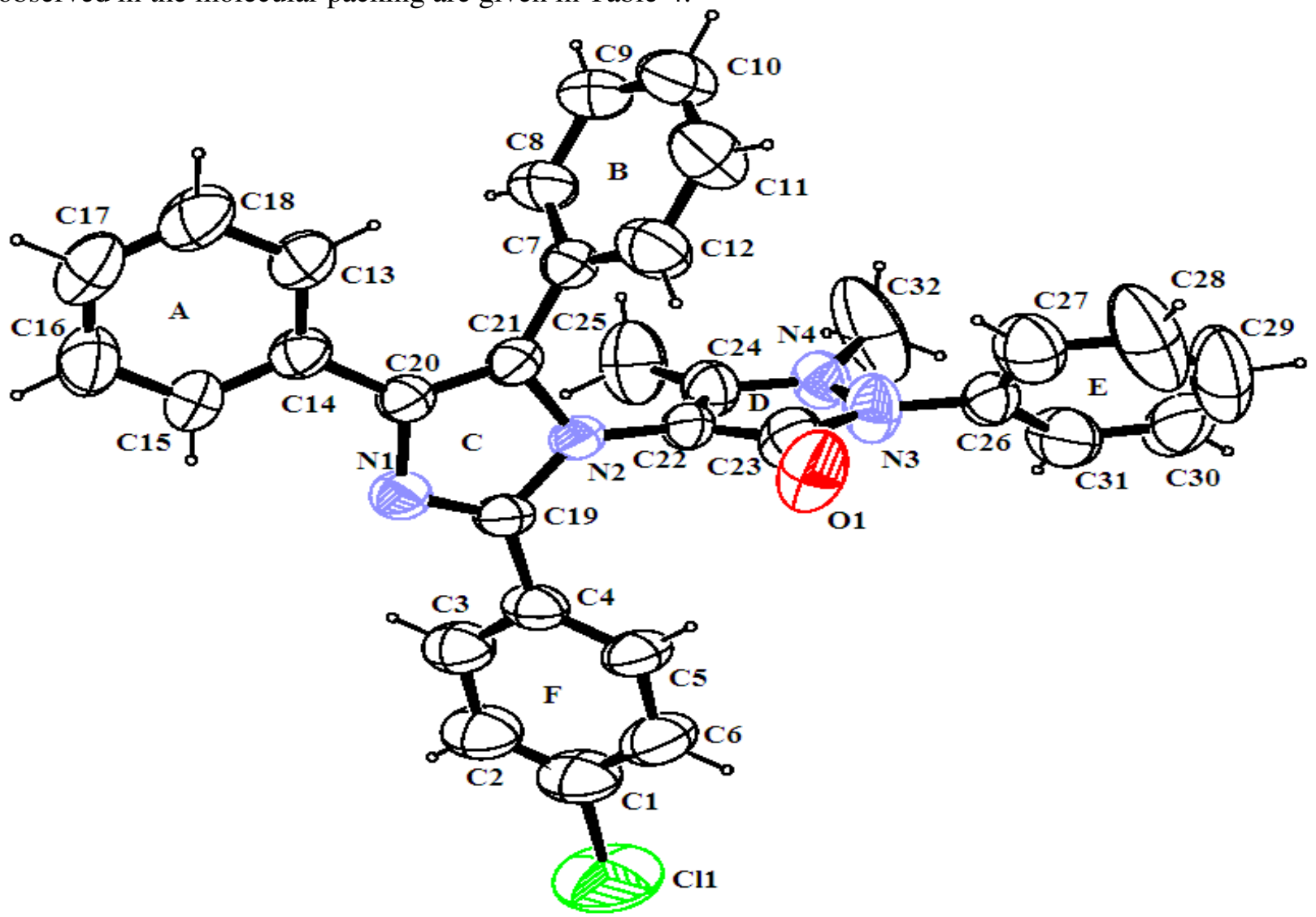

Fig.-2:ORTEP View of the Molecule at a 40\% Displacement Ellipsoid Probability Level along with the Atomic Labeling Scheme. Hydrogen Atoms are Drawn at Arbitrary Radii.

Table-1: Crystal and Structure-Refinement Data for $\mathrm{C}_{32} \mathrm{H}_{25} \mathrm{ClN}_{4} \mathrm{O}$.

\begin{tabular}{c|c}
\hline CCDC Number & 1507484 \\
\hline System, Space group, $\mathrm{Z}$ & Monoclinic, $\mathrm{P} 2_{1} / \mathrm{c}, 4$ \\
\hline$a, b, c(\AA)$ & $7.7847(7), 17.5077(14), 19.8332(19)$ \\
\hline$\beta\left(^{\circ}\right)$ & $92.783(8)$ \\
\hline $\mathrm{V}\left(\AA^{3}\right)$ & $2699.9(4)$ \\
\hline$D_{\mathrm{x}}{\mathrm{g} . \mathrm{cm}^{-3}}^{-3}$ & 1.272 \\
\hline Radiation, $\lambda, \AA$ & 0.71073 \\
\hline$\mu, \mathrm{mm}^{-1}$ & 0.174 \\
\hline
\end{tabular}


RASĀYAN J. Chem.

Vol. 12 | No. 2 |773 - 779| April - June | 2019

\begin{tabular}{c|c}
\hline $\mathrm{T}, \mathrm{K}$ & $293(2)$ \\
\hline Sample size, $\mathrm{mm}^{3}$ & $0.30 \times 0.20 \times 0.20$ \\
\hline Diffractometer & $0.79244,1.00000$ \\
\hline Scan mode & 3.50 to 24.99 \\
\hline $\mathrm{T}_{\min ,}, \mathrm{T}_{\max }$ & $\mathrm{X}^{\prime}$ calibur Sapphire3 CCD area-detector \\
\hline$\theta$ range, deg & $9883 / 4705$ \\
\hline$h, k, l$ ranges & 1944 \\
\hline Reflections total/unique & 0.103 \\
\hline Reflections observed $[\mathrm{I}>2 \sigma(\mathrm{I})]$ & 1080 \\
\hline $\mathrm{R}_{\text {int }}$ & 0.0853 \\
\hline $\mathrm{F}(000)$ & 0.1863 \\
\hline $\mathrm{R}$ & 0.017 \\
\hline$w \mathrm{R}\left[\mathrm{F}^{2}\right]$ & 346 \\
\hline$(\Delta / \sigma)_{\max }$ & 0.924 \\
\hline $\mathrm{S}$ & $0.27,-0.28$ \\
\hline Number of refined parameters & SHELXS97 ${ }^{12}, \mathrm{SHELXL}^{12}, \mathrm{PARST}^{14}$, PLATON $^{15}$, \\
\hline$\Delta \rho_{\max }, \Delta \rho_{\min }\left(\mathrm{e} \AA^{-3}\right)$ & ORTEP $^{16}$, MERCURY $^{20}$ \\
\hline Programs &
\end{tabular}

Table-2: Selected Bond Distances, Bond Angles and Torsion Angles.

\begin{tabular}{|c|c|c|c|}
\hline \multicolumn{2}{|c|}{ Bond Distances $(\AA)$} & \multicolumn{2}{|c|}{ Bond Distances $(\AA)$} \\
\hline $\mathrm{C} 2-\mathrm{C} 1$ & $1.378(7)$ & $\mathrm{C} 21-\mathrm{C} 20$ & $1.371(5)$ \\
\hline $\mathrm{C} 2-\mathrm{C} 3$ & $1.400(6)$ & $\mathrm{C} 22-\mathrm{C} 23$ & $1.418(6)$ \\
\hline C4-C3 & $1.387(6)$ & C22-C24 & $1.341(6)$ \\
\hline C4-C5 & $1.379(6)$ & $\mathrm{C} 25-\mathrm{C} 24$ & $1.481(6)$ \\
\hline C5-C6 & $1.391(6)$ & $\mathrm{C} 27-\mathrm{C} 26$ & $1.365(7)$ \\
\hline C6-C1 & $1.369(7)$ & $\mathrm{C} 27-\mathrm{C} 28$ & $1.376(8)$ \\
\hline $\mathrm{C} 8-\mathrm{C} 7$ & $1.379(6)$ & $\mathrm{C} 28-\mathrm{C} 29$ & $1.359(12)$ \\
\hline C8-C9 & $1.387(6)$ & C30-C29 & $1.334(11)$ \\
\hline C9-C10 & $1.361(7)$ & $\mathrm{C} 31-\mathrm{C} 26$ & $1.364(6)$ \\
\hline C11-C10 & $1.377(7)$ & C31-C30 & $1.392(9)$ \\
\hline $\mathrm{C} 11-\mathrm{C} 12$ & $1.392(6)$ & C32-N4 & $1.403(5)$ \\
\hline $\mathrm{C} 12-\mathrm{C} 7$ & $1.380(6)$ & $\mathrm{Cl1}-\mathrm{C} 1$ & $1.738(5)$ \\
\hline C14-C13 & $1.378(5)$ & $\mathrm{N} 1-\mathrm{C} 20$ & $1.390(5)$ \\
\hline C14-C15 & $1.396(5)$ & N2-C19 & $1.381(4)$ \\
\hline $\mathrm{C} 14-\mathrm{C} 20$ & $1.472(5)$ & $\mathrm{N} 2-\mathrm{C} 21$ & $1.395(5)$ \\
\hline C16-C15 & $1.389(6)$ & $\mathrm{N} 2-\mathrm{C} 22$ & $1.423(4)$ \\
\hline C16-C17 & $1.365(6)$ & N3-C23 & $1.401(5)$ \\
\hline C18-C13 & $1.389(6)$ & N3-C26 & $1.425(5)$ \\
\hline $\mathrm{C} 18-\mathrm{C} 17$ & $1.376(7)$ & N3-N4 & $1.385(5)$ \\
\hline $\mathrm{C} 19-\mathrm{C} 4$ & $1.469(5)$ & N4-C24 & $1.360(5)$ \\
\hline C19-N1 & $1.326(4)$ & $\mathrm{O} 1-\mathrm{C} 23$ & $1.234(5)$ \\
\hline $\mathrm{C} 21-\mathrm{C} 7$ & $1.474(5)$ & & \\
\hline
\end{tabular}

\begin{tabular}{c|c|c|c}
\hline \multicolumn{2}{c|}{${\text { Bond Angles }\left({ }^{\circ}\right)}^{2}$ Bond Angles $\left.{ }^{\circ}\right)$} \\
\hline C2-C1-Cl1 & $119.4(5)$ & N1-C20-C14 & $119.3(3)$ \\
\hline C6-C1-C11 & $119.2(5)$ & C20-C21-N2 & $105.9(3)$ \\
\hline C20-C21-C7 & $134.3(4)$ & N2-C21-C7 & $119.8(3)$ \\
\hline C3-C4-C19 & $121.6(4)$ & C24-C22-C23 & $109.9(3)$ \\
\hline C23-C22-N2 & $123.7(4)$ & C24-C22-N2 & $125.4(4)$ \\
\hline
\end{tabular}


RASĀYAN J. Chem.

Vol. 12 | No. 2 |773 - 779| April - June | 2019

\begin{tabular}{c|c|c|c}
\hline C5-C4-C19 & $118.2(4)$ & N3-C23-C22 & $103.5(4)$ \\
\hline C23-N3-C26 & $126.7(4)$ & O1-C23-C22 & $132.2(4)$ \\
\hline C21-N2-C22 & $124.0(3)$ & O1-C23-N3 & $124.2(4)$ \\
\hline C8-C7-C21 & $121.0(4)$ & C22-C24-C25 & $128.1(4)$ \\
\hline C12-C7-C8 & $117.7(4)$ & C22-C24-N4 & $109.5(4)$ \\
\hline C12-C7-C21 & $121.3(4)$ & N4-C24-C25 & $122.4(4)$ \\
\hline C13-C14-C20 & $119.6(4)$ & C27-C26-N3 & $117.9(4)$ \\
\hline C19-N2-C21 & $106.9(3)$ & C31-C26-C27 & $120.8(5)$ \\
\hline C19-N2-C22 & $128.5(3)$ & C31-C26-N3 & $121.3(5)$ \\
\hline N1-C19-C4 & $124.4(3)$ & N4-N3-C23 & $109.9(3)$ \\
\hline C15-C14-C20 & $122.5(3)$ & C19-N1-C20 & $106.1(3)$ \\
\hline N1-C19-N2 & $111.0(3)$ & N4-N3-C26 & $123.0(3)$ \\
\hline N2-C19-C4 & $124.6(3)$ & C24-N4-C32 & $125.9(4)$ \\
\hline 221-C20-C14 & $130.6(4)$ & C24-N4-N3 & $107.0(3)$ \\
\hline C21-C20-N1 & $110.1(3)$ & N3-N4-C32 & $124.9(3)$ \\
\hline
\end{tabular}

\begin{tabular}{c|c|c|c}
\hline \multicolumn{2}{c|}{ Torsion Angles $^{\circ}$ ) } & \multicolumn{2}{c}{ Torsion Angles ${ }^{\circ}$ ) } \\
\hline N2-C22-C23-N3 & $-172.8(4)$ & N2-C22-C23-O1 & $9.7(9)$ \\
\hline N2-C22-C24-N4 & $173.4(4)$ & N2-C22-C24-C25 & $-7.9(8)$ \\
\hline C22-N2-C19-N1 & $-171.6(4)$ & C22-N2-C19-C4 & $7.6(7)$ \\
\hline 113-C14-C20-N1 & $-12.1(6)$ & C22-N2-C21-C7 & $-6.1(6)$ \\
\hline C15-C14-C20-C21 & $-9.2(7)$ & C22-N2-C21-C20 & $172.4(4)$ \\
\hline C15-C14-C20-N1 & $168.2(4)$ & C19-N2-C22-C23 & $-102.5(5)$ \\
\hline C21-N2-C22-C23 & $88.2(5)$ & C19-N2-C22-C24 & $89.4(6)$ \\
\hline C26-N3-C23-C22 & $174.9(4)$ & C21-N2-C22-C24 & $-79.9(6)$ \\
\hline N1-C19-C4-C3 & $-137.9(4)$ & C26-N3-C23-O1 & $-7.3(8)$ \\
\hline 11-C19-C4-C5 & $38.5(7)$ & N2-C19-C4-C3 & $43.0(7)$ \\
\hline N2-C19-C4-C5 & $-140.6(4)$ & C23-N3-C26-C27 & $-48.3(7)$ \\
\hline C13-C14-C20-C21 & $170.5(5)$ & C23-N3-C26-C31 & $132.0(5)$ \\
\hline C32-N4-C24-C25 & $14.4(8)$ & N4-N3-C26-C27 & $124.6(5)$ \\
\hline C20-C21-C7-C8 & $109.8(6)$ & N4-N3-C26-C31 & $-55.1(6)$ \\
\hline C20-C21-C7-C12 & $-71.8(6)$ & C32-N4-C24-C25 & $14.4(8)$ \\
\hline N2-C21-C7-C8 & $-72.1(6)$ & C23-N3-N4-C32 & $165.1(5)$ \\
\hline N2-C21-C7-C12 & $106.3(5)$ & C26-N3-N4-C24 & $-173.0(4)$ \\
\hline C7-C21-C20-C14 & $-5.3(8)$ & C26-N3-N4-C32 & $-8.9(8)$ \\
\hline
\end{tabular}

Table-3: Hydrogen Bonding Geometry (e.s.d.`s in Parentheses)

\begin{tabular}{c|c|c|c|c}
\hline $\mathrm{D}-\mathrm{H} \ldots \mathrm{A}$ & $\mathrm{D}-\mathrm{H}(\AA)$ & $\mathrm{H} \ldots \mathrm{A}(\AA)$ & $\mathrm{D} \ldots \mathrm{A}(\AA)$ & $\mathrm{D}-\mathrm{H} \ldots \mathrm{A}\left({ }^{\circ}\right)$ \\
\hline $\mathrm{C} 13-\mathrm{H} 13 \ldots \mathrm{N} 1$ & 0.93 & 2.50 & $2.8441(3)$ & 102 \\
\hline $\mathrm{C} 16-\mathrm{H} 16 \ldots \mathrm{O} 1^{\mathrm{i}}$ & 0.93 & 2.45 & $3.3722(3)$ & 171 \\
\hline
\end{tabular}

Symmetry code: (i) $-\mathrm{x}, 1 / 2+\mathrm{y}, 1 / 2-\mathrm{z}$

Table-4: Geometry of C-H... $\pi$ Interaction*

\begin{tabular}{c|c|c|c|c}
\hline D-H...Cg & D-H $(\AA)$ & H...Cg $(\AA)$ & D $\ldots C g(\AA)$ & D-H...Cg $\left({ }^{\circ}\right)$ \\
\hline $\mathrm{C} 32-\mathrm{H} 32 \mathrm{~A} \ldots \mathrm{Cg} 1^{\mathrm{i}}$ & 0.93 & 2.80 & $3.6485(3)$ & 147 \\
\hline
\end{tabular}

Symmetry code: (i) $1+x, y, z$

* Cg1 represent the center of gravity of imidazole(C) ring.

\section{CONCLUSION}

The structure of 4-(2-(4-Chlorophenyl)-4,5-diphenyl-1H-imidazole-1-yl)-2,3-dimethyl-1-phenyl-1,2dihydropyrzol-5-one consists of six rings, four are bonded to the central imidazole ring and one phenyl to the pyrazole ring. All the rings are almost planar. The pyrazole ring is held almost right angle to the imidazole ring as indicated by the dihedral angle being $89.46^{\circ}$. The $\mathrm{C}-\mathrm{H} \cdots \mathrm{O}$ intermolecular and $\mathrm{C}$ - 
$\mathrm{H} . . . \mathrm{N}$ intra-molecular hydrogen bond connects the molecule into a three-dimensional network. C-H... $\pi$ contacts have also been observed in the molecular packing.

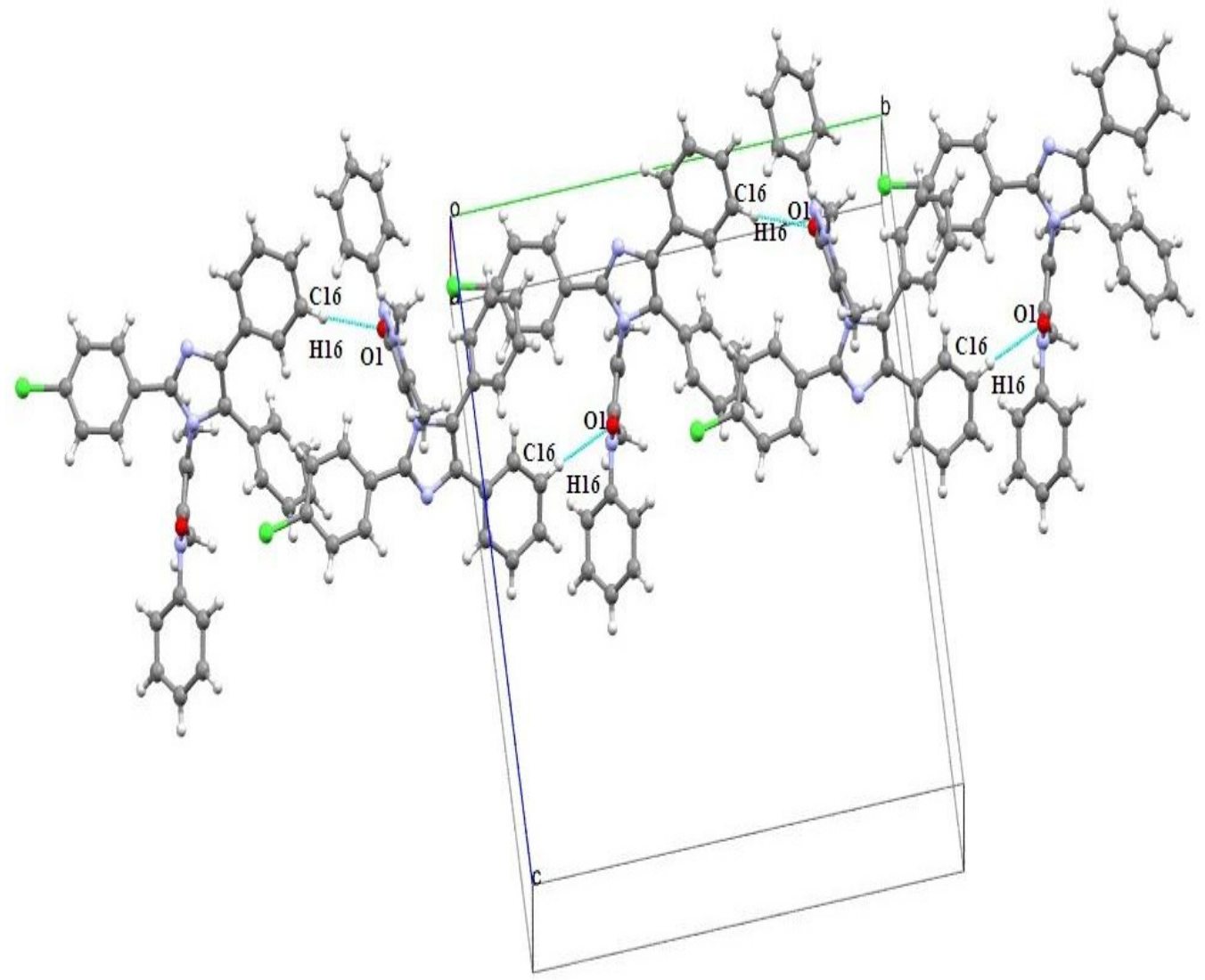

Fig.-3: Intermolecular Hydrogen Bonds Link the Molecule into Infinite Chains Along b-Axis.

\section{ACKNOWLEDGMENT}

RK acknowledges the Department of Science and Technology Research Project No EMR/2014/000467. BN thanks the UGC for financial assistance through BSR one time grant for the purchase of chemicals. AJ thanks University Grants Commission, New Delhi, for providing financial support for the research work through Junior Research Fellowship.

\section{REFERENCES}

1. A. M. Vijesh, A. M. Isloorx, S. Telkar, S. K. Peethambar, R. Sankappa and N. Isloor, Eur. J. Med. Chem., 46, 3531 (2011), DOI:10.1016/j.ejmech.2011.05.005

2. M. Pinza, Z. Farina, A. Cerri, U. Pfeiffer, M. T. Riccaboni, S. Banfi, R. Biagetti, O. Pozzi, M. Magnani and L. Dorigotti, J. Med. Chem., 36, 4214 (1993), DOI:10.1021/jm00078a011

3. J. Pandey, V. K. Tiwari, S. S. Verma, V. Chaturvedi, S. Bhatnagar, S. Sinha, A. N. Gaikwad and R. P. Tripathi, Eur. J. Med. Chem., 44, 3350 (2009), DOI:10.1016/j.ejmech.2009.02.013

4. F. Suzuki, T. Kuroda, T. Tamura, S. Sato, K. Ohmori and S. Ichikawa, J. Med. Chem., 35, 2863 (1992), DOI: 10.1021/jm00093a020

5. I. Takeuchi, M. Sugiura, K. Yamamoto, T. Ito and Y. Hamada, Yakuga. Zasshi.,105, 554 (1985).

6. H. Miyachi, H. Kiyota and M. Segawa, Bioorg. Med. Chem. Lett.,8, 1807 (1998), DOI: 10.1016/S0960-894X(98)00312-6

7. C. Alka, P. K. Sharma and K. Niranjan, Int. J. Chem. Tech. Res., 3, 11 (2011).

8. A. M. Isloor, B. Kalluraya and P. Shetty, Eur. J. Med. Chem., 44, 3784 (2009), DOI: $10.1016 /$ j.ejmech.2009.04.038 
RASĀYAN J. Chem.

Vol. 12 | No. 2 |773 - 779| April - June | 2019

9. A. M. Isloor, B. Kalluraya and M. Rao, J. Saudi Chem. Soc., 4, 265 (2000).

10. B. Kalluraya, A. M. Isloor, P. V. Frank, R. L. Jagadesha and S. Shenoy, Indian J. Heterocycl. Chem.,11, 159 (2001).

11. D. Sunil, A. M. Isloor and P. Shetty, Der Pharma Chemica.,1, 19 (2009).

12. G. M. Sheldrick, Acta. Cryst.,A64, 112 (2008), DOI:10.1107/S0108767307043930

13. L. J. Farrugia, Journal of Applied Crystallography, 32, 837 (1999), DOI:10.1107/S0021889899006020

14. M. Nardelli, Journal of Applied Crystallography, 28, 659 (1995), DOI: 10.1107/S0021889895007138

15. A. L. Spek, Acta Crystallographica, D65, 148 (2009), DOI: 10.1107/S090744490804362X

16. L. J. Farrugia, Journal of Applied Crystallography, 30, 565 (1997), DOI: $10.1107 / \mathrm{S} 0021889897003117$

17. F. H. Allen, O. Kennard, D. G. Watson, L. Brammer, A. G. Orpen and R. Taylor, Journal of the Chemical Society Perkin Transactions, 2, S1(1987), DOI:10.1039/P298700000S1

18. S. K. Mohamed, M. Akkurt, A. A. Marzouk, V. M. Abbasov and A. V. Gurbanov, ActaCryst., E69, o474 (2013), DOI:10.1107/S1600536813004285

19. M. Akkurt, F. R. Fronczek, S. K. Mohamed, A. H. Talybov, A. A. E. Marzouk and A. A. Abdelhamid, ActaCryst.,E69, o527 (2013), DOI: 10.1107/S1600536813006326

20. C. F. Macrae, P. R. Edgington, P. McCabe, E. Pidcock, G. P. Shields, R.Taylor, M. Towler, J. Van de Streek and P. A. Wood, J. Appl. Cryst., 41, 466 (2008), DOI: 10.1107/S0021889807067908

[RJC-5157/2018] 